\title{
La patrimonialización del megalitismo en el Andévalo
}

El fenómeno del Megalitismo, que en un amplio marco espacio-temporal podríamos circunscribir al occidente europeo entre el 2600 y el 1900 a.n.e., adquiere una singular trascendencia en el suroeste peninsular por su riqueza y diversidad tipológica. En concreto, la provincia de Huelva, Extremadura, el Algarve y el Bajo Alentejo conforman un espacio donde este tipo de manifestaciones culturales resultan especialmente abundantes

El Andévalo onubense, espacio de transición entre la planicie litoral y los abruptos relieves de la zona serrana, es el sector de la provincia de Huelva donde mayor concentración de estructuras megalíticas encontramos, siendo abundantes las variantes y las soluciones arquitectónicas desarrolladas, que de manera simplificada podriamos agrupar en: dólmenes simples, sepulcros de corredor y galerías cubiertas.

Si bien en la provincia de Huelva se localizan multitud de vestigios materiales integrantes de la cultura megalítica, alguno de ellos especialmente relevante a nivel europeo como el Dolmen de Soto, dos grandes conjuntos megalíticos, el de Los Gabrieles (Valverde del Camino) y El Pozuelo (Zalamea la Real) son los máximos exponentes de la cultura dolménica en la comarca del Andévalo.

La construcción de estos grandes monumentos funerarios parece obedecer, más que a una intención exclusivamente ritual o funeraria, a un intento de conformar un hito visual $y$, sobre todo, simbólico, del ámbito territorial del grupo humano que los hizo construir. De esta forma podemos deducir que su uso funerario pudiera constituir el "pretexto" para levantar una serie de estructuras, visibles desde lugares más o menos lejanos, para expresar la ocupación y el control territorial del grupo. Por otra parte su construcción y la aparición de los elementos y piezas arqueológicas, halladas en su interior y en su entorno, nos permiten deducir ciertos aspectos de su complejidad social y de la economía inherentes a la sociedad de sus constructores: una sociedad de ganaderos y agricultores/recolectores, además de cazadores, que parecen empezar a descubrir el amplio mundo de la minería y de la metalurgia, que tendrá una mayor vigencia y esplendor en periodos posteriores.

El grupo dolménico de Los Gabrieles, descubierto por José Ma Luzón en 1966 y con una extensión de casi un kilómetro cuadrado, está conformado por seis dólmenes de galeria cubierta. Los dólmenes 2 y 6 formarían una primera agrupación mientras que los dólmenes 3, 4 y 5 serían el núcleo del conjunto, quedando el dolmen $n^{\circ} 1$ algo más aislado.

El estudio de los materiales hallados en sucesivas excavaciones, de sus grabados y tipología constructiva, nos permite determinar que se trata de unas construcciones de la segunda mitad del III a.C., dentro del ámbito cronológico del Calcolítico, aunque podamos constatar la reutilización de los monumentos en los siglos VII y VI a.n.e.

En el caso de los dólmenes de El Pozuelo nos encontramos con una gran necrópolis de al menos dieciséis tumbas, enmarcadas temporalmente en torno al 2500-2200 a.n.e. y con tipologías diferentes, entre las que destacan las de corredor y cámara simple y las de cámara múltiple, características por la originalidad y cierta complejidad de sus plantas.

La información proporcionada por las últimas investigaciones permite pensar en un entorno natural en el que predominaría un paisaje de monte de encinas $y$ alcornoques, junto a chopos $y$ fresnos en las zonas más húmedas, en un ámbito climático mediterráneo, con valores similares a los actuales.

Los conjuntos dolménicos descritos conforman un itinerario cultural coherente dotado de una elevada homogeneidad que ha de ser difundido y puesto en valor desde una óptica relacional unitaria, contextualizada, eso sí, en sus respectivos enclaves territoriales pero netamente enraizada en un sustrato sociocultural que es común a estas arquitecturas megaliticas que se materializan en rangos cronológicos concertados desde un registro material común.

La Consejeria de Cultura ha apostado por una estrategia de puesta en valor fundada en la generación de una serie de centros de recepción de visitantes que pretenden la contextualización en un entorno inmediato de estos bienes patrimoniales que complemen$\tan$ y basculan en torno al futuro centro de cabecera de Antequera, apostando asi por la conformación de redes culturales de neta vocación regional, nacional e incluso transfronteriza.

El acercamiento a los objetivos de difusión se ha realizado a tres niveles de registro, la difusión general, la científico técnica, sin olvidar la necesaria traslación a los programas curriculares educativos de primaria y secundaria y a la formación del propio profesorado.

Las actuaciones de consolidación preventiva y de restauración tendentes a posibilitar la visita pública de estos bienes y garantizar su conservación, su señalización unitaria, el reforzamiento de los contenidos vertebradores, el fomento de la investigación disciplinar y la incardinación de estos itinerarios dentro de las redes de senderismo y caminos rurales así como de los planes estratégicos de turismo que permitan hacer accesibles estos enclaves desde estrategias comunes a otras áreas disciplinares como las de orden medioambiental o turistica de fuerte enraizamiento en sustratos culturales, se erigen en estrategias de gestión patrimonial con relación al objetivo de puesta en valor y socialización de este patrimonio histórico.

Juan José Fondevilla Aparicio

Jefe de Servicio de Bienes Culturales. Delegación

Provincial de Huelva

Javier Rastrojo Luna

Arqueólogo. Delegación Provincial de Huelva
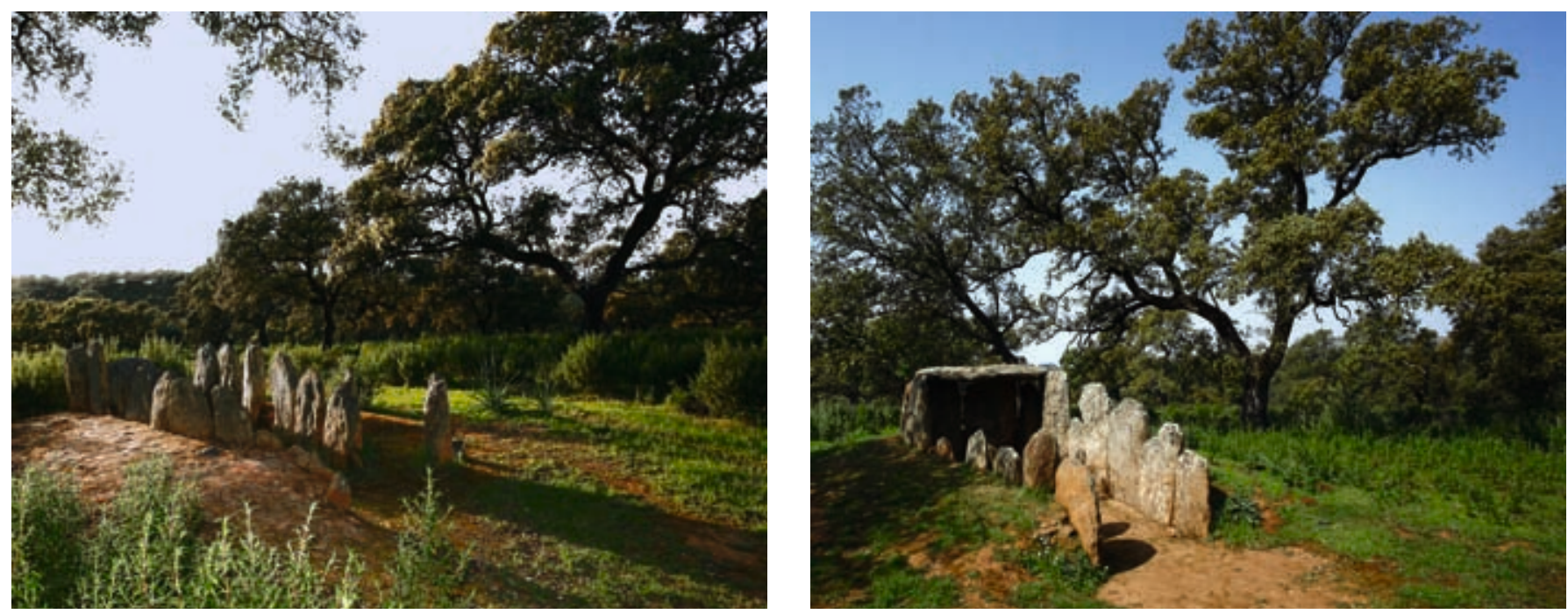

Grupo dolménico Los Gabrieles (Valverde del Camino). Fotos: Miguel Ángel Blanco de la Rubia 